\title{
Apoptotic phenotype induced by overexpression of wild-type gas3/PMP22: its relation to the demyelinating peripheral neuropathy CMT1A
}

\author{
Elsa Fabbretti, ${ }^{1}$ Paolo Edomi, ${ }^{2}$ Claudio Brancolini, ${ }^{1,3}$ and Claudio Schneider ${ }^{1,3,4}$ \\ ${ }^{1}$ Laboratorio Nazionale Consorzio Intenuniversitario Biotecnologie, 34012 Trieste, Italy; ${ }^{2}$ Department of Biology, Universita' \\ degli Studi di Trieste, Trieste 34127, Italy; ${ }^{3}$ Faculty of Medicine, Universita' degli Studi di Udine, 33100 Udine, Italy
}

\begin{abstract}
Although the Gas3/PMP22 protein is expressed at highest levels in differentiated Schwann cells, its presence, albeit at lower levels, in non-neuronal tissues and in NIH-3T3 growth-arrested fibroblasts argues for a more general function of this protein that is uncoupled to myelin structure. We show that gas3/PMP22 overexpression in NIH-3T3 growing cells leads to an apoptotic-like phenotype, which is suppressed by antioxidants and characterized by typical membrane blebbing, rounding up, and chromatin condensation, but with no evidence of DNA fragmentation. REF-52 fibroblasts seem to be completely refractive to gas3/PMP22 overexpression. Recently, several point mutations of the human gas3/PMP22 gene have been associated with Charcot-Marie-Tooth type 1A (CMT1A), a common hereditary demyelinating neuropathy. When gas3/PMP22 point mutations $(L 16 P, S 79 C, T 118 M$, and $G 150 D)$ are similarly overexpressed in NIH-3T3 cells, the induced apoptotic-like phenotype as compared to the wild-type is significantly reduced. Both of the dominant mutations (L16P, S79C) for CMT1A behave as dominant negatives with respect to the wild type, whereas $T 118 M$, the only recessive mutant described, behaves as recessive under the same coexpression experiments. These data suggest a role for altered Schwann cell apoptosis in the pathogenesis of CMT1A.
\end{abstract}

[Key Words: Apoptosis; Charcot-Marie-Tooth 1A; gas3; PMP22]

Received March 31, 1995; revised version accepted June 20, 1995.

gas3, originally isolated from NIH-3T3 cells for its growth arrest-dependent expression (Schneider et al. 1988; Manfioletti et al. 1990), has been subsequently characterized as a major component of the peripheral nerve myelin and named accordingly as peripheral myelin protein PMP22 (Spreyer et al. 1991; Welcher et al. 1991; Snipes et al. 1992). gas3/PMP22 is abundantly expressed in differentiated myelin-forming Schwann cells, but it is dramatically down-regulated after nerve injury when Schwann cell proliferation starts (Spreyer et al. 1991; Welcher et al. 1991), thus indicating that its $G_{0^{-}}$. dependent expression also holds true in vivo. It encodes for an integral membrane protein presenting four putative transmembrane domains with an apparent molecular mass of $22 \mathrm{kD}$ (Snipes et al. 1992).

Genetic studies have revealed that the gas $3 / P M P 22$ gene is responsible for a set of inherited peripheral neuropathies in mice and humans. Myelin deficiency in peripheral nerve and continued Schwann cell proliferation

${ }^{4}$ Corresponding author. are the main histological characteristics of the mutated phenotypes, whereas impaired conduction of nerve impulses is the major pathological symptom (Suter et al. 1993).

In rodents, point mutations of gas $3 /$ PMP22 are associated with the peripheral neuropathy phenotype Trem. bler and Trembler) (Suter et al. 1992a,b). Point mutations in gas $3 /$ PMP22 have been reported in $\sim 30 \%$ of CharcotMarie-Tooth 1A (CMT1A) patients (Valentijn et al. 1992a; Ionasescu et al. 1993; Roa et al. 1993a,b), the other cases being accounted for by a large duplication of the short arm of chromosome 17 containing the gas3/ PMP22 locus (Lupski et al. 1991; Matsunami et al. 1992; Timmerman et al. 1992; Valentijn et al. 1992b; Roa et al. 1993a,b).

Further studies have confirmed the crucial role of Gas3/PMP22 in the demyelinating neuropathies. Dejerine-Sottas syndrome, showing similar but more severe symptoms than CMT1A, is also characterized by point mutations in gas3/PMP22 (Roa et al. 1993c). Furthermore gas3/PMP22 has also been implicated in other forms of peripheral neuropathies: Hereditary neuropathy 
with liability to pressure palsies (HNPP-tomaculous neuropathyl is associated with a deletion of the same chromosomal region containing gas3/PMP22 duplicated in CMT1A patients (Chance et al. 1993).

These studies have revealed two surprising findings: (1) that a variety of genetic mechanisms involving gas3/ PMP22, including point mutations, duplication, and deletions, may give rise to distinct hereditary peripheral neurophaties; and (2) two different genetic mechanisms (duplication and point mutations) can result in similar clinical phenotypes of CMT1A (Patel and Lupski 1994).

Identification of functional or phenotypic differences between gas3/PMP22 wild-type and point mutation derivatives should thus represent a first step toward the understanding of its involvement in CMT1A. To date, however, no phenotype and thus no biological function for Gas3/PMP22 has been established. Our initial observation of Gas3/PMP22 suggested a possible function in regulating some general aspects of cell proliferation. Its expression is increased at growth arrest in NIH-3T3 cells and is down-regulated in association with carcinogenesis in non-neuronal tissues such as lung, where it is also expressed (Re et al. 1992).

In this report we have extended the findings of our initial model system and demonstrate that expression of gas3/PMP22 in NIH-3T3 cells leads to a phenotype similar to apoptosis. Furthermore, we show a correlation between phenotypic dominant or recessive behaviors, and dominant and recessive modes of inheritance for the various CMT1A and Trembler point mutation alleles analyzed.

\section{Results}

Expression of gas3/PMP22 product in $\mathrm{NIH}-3 \mathrm{~T} 3$ cells and in mouse PNS tissues

Antiserum against mouse Gas3/PMP22 protein, raised in rabbit against the putative extracellular domain of mGas3 (amino acids 16-63, presenting 98\% identity between mouse and rat), was affinity purified as described in Materials and methods. Western immunoblot analysis of total protein isolated from rat sciatic nerves (Fig. 1A, lane 1) shows that the antibody recognizes a major band of $22 \mathrm{kD}$ and a minor band of $18 \mathrm{kD}$, in agreement with previous studies (Welcher et al. 1991).

Lysates were treated with $\mathrm{N}$-glycosydase F (PNGase F), which removes Asn-linked oligosaccharide chains, to identify the $18 \mathrm{kD}$ protein as the Gas3/PMP22 precursor. After this treatment the anti-mGas3/PMP22 antibody recognized only one molecular species of $18 \mathrm{kD}$ apparent size, with the same mobility as the lower band in untreated rat sciatic nerve lysates (Fig. 1A, lane 2). Interestingly pretreatment of serum-starved NIH-3T3 extracts with PNGase $\mathrm{F}$ allowed detection of a band comigrating with the unglycosylated form of Gas3/ PMP22 in rat sciatic nerve (Fig. 1A, lane 4). Conversely we could not detect Gas3/PMP22 protein with antimGas3/PMP22 antibody in the untreated cell lysates (Fig. 1A, lane 3). This is probably attributable to epitope

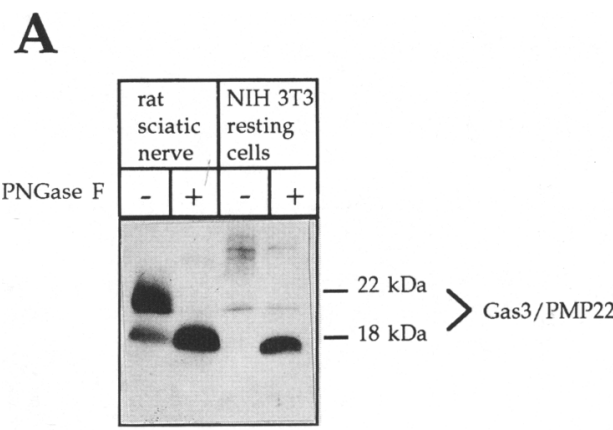

B

HOURS AFTER ADDITION OF 0,5\% FCS

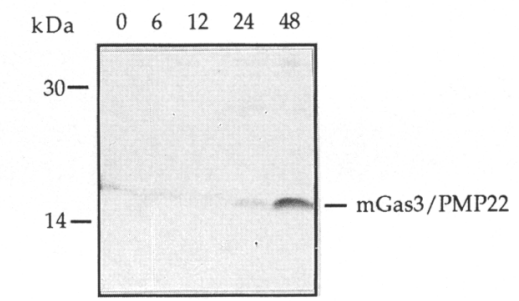

C

DAYS AFTER SEEDING IN $10 \%$ FCS

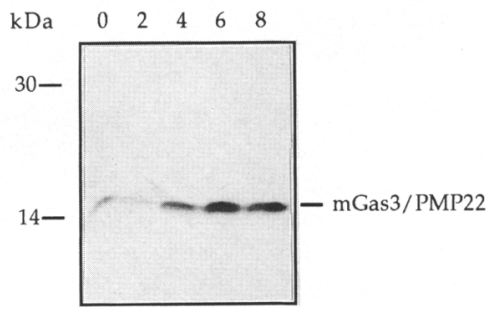

Figure 1. Western blot analysis of Gas3/PMP22 expression in PNS and NIH-3T3 cells. (A) Tissue and cellular extracts were treated with or without PNGase F as described in Materials and methods. As a positive control, rat sciatic nerve extract, untreated $(-)$ or treated $|+|$ with PNGase $F$, was used. The amount of rat sciatic nerve protein loaded (lane 1,2 ) was $40 \times$ less than the resting NIH-3T3 lysates (lane 3,4). (B) PNGase F-treated lysates from actively growing NIH-3T3 cells and various times after serum starvation. $(C)$ PNGase F-treated lysates from exponentially growing NIH-3T3 cells and various days after cell seeding. Western blot analysis was performed using affinity-purified anti-mGas3/PMP22 antibody.

masking because the consensus site of $N$-glycosylation lies at position 41 within the region of $\mathrm{mGas} 3 / \mathrm{PMP} 22$ used as immunogen. Recognition of the mGas3/PMP22 glycosylated form as expressed in peripheral nerves by the same anti-mGas3/PMP22 could depend on Schwann cell-specific processing of the mature carbohydrate moiety. Similar behavior of anti-mGas3/PMP22 antibodies has already been reported for antibodies raised against a synthetic peptide of rat Gas3/PMP22 comprising the consensus site for $\mathrm{N}$-glycosylation (Pareek et al. 1993). We conclude that anti-mGas3/PMP22 antibody reacts 
with mature and precursor forms of Gas3/PMP22 protein expressed in rat sciatic nerve and with only the unglycosylated form in NIH-3T3 mouse fibroblasts. Moreover, in peripheral nervous system (PNS) tissues Gas3/ PMP22 protein is expressed $\sim 200$ times more compared with that in growth-arrested NIH-3T3 cells.

Because expression of gas $3 / P M P 22$ mRNA is induced at growth arrest by either serum starvation or saturation density in NIH-3T3 cells (Manfioletti et al. 1990), we examined whether the protein was similarly expressed under both conditions. Expression of mGas3/PMP22 was thus analyzed during growth arrest induced by both serum starvation and saturation density by Western immunoblot analysis. Equal protein amounts of PNGase $F$-treated extracts were loaded for each time point (as assessed by Coomassie blue staining of separate gels). Figure 1B shows the kinetics of the appearance of Gas3/ PMP22 protein after serum depletion from exponentially growing NIH-3T3 cells. As expected, Gas3/PMP22 protein appears as a band with an apparent molecular mass of $18 \mathrm{kD}$ in all lanes: Its level is significantly increased $48 \mathrm{hr}$ after serum starvation. A similar increase in expression of Gas3/PMP22 is observed during density-dependent inhibition (Fig. 1C). These results are thus in agreement with the previous analysis of mRNA expression (Manfioletti et al. 1990) indicating that Gas3/ PMP22 protein levels are increased under different growth arrest conditions .

\section{Expression of Gas3/PMP22 protein in non-neuronal rat and human tissues}

Because we were able to show that Gas3/PMP22 protein is expressed in NIH-3T3 mouse fibroblasts, we investigated whether it is present in rat and human non-neuronal tissues. Figure 2 shows the results of Western analysis on rat tissue lysates pretreated with PNGase F be- fore SDS-PAGE. An 18-kD band of the same relative mobility as the one in rat sciatic nerve is present in lung and intestine, and a faint band can also be seen in kidney (Fig. 2A). Thus, Gas3/PMP22 protein is expressed abundantly in sciatic nerve but is also present, albeit at much lower relative levels, in non-neuronal rat tissues in agreement with previous Northern analysis data (Welcher et al. 1991; Spreyer et al. 1991).

We decided to confirm this pattern of Gas $3 /$ PMP22 expression in different human tissues. For this purpose, antiserum against human Gas3/PMP22 was raised in rabbit against the putative extracellular domain of hGas3 (from amino acids 16 to 63 ), which presents $79 \%$ amino acid identity with the same region of mouse protein. Affinity-purified antibodies specific for hGas3/ PMP22 were used in Western analysis on different human tissues. The anti-hGas3/PMP22 antibody recognizes a molecular species of $22 \mathrm{kD}$ and additional lower size bands in human phrenic nerve (Fig. 2B). The pattern in human phrenic nerve is similar to the rat sciatic nerve with the notable difference of a third lowest size band that probably represents a proteolytic fragment generated by postmortem autolysis. When the lysates were treated with PNGase $\mathrm{F}$ before Western analysis, the mobility of the $22-\mathrm{kD}$ band relative to the mature Gas $3 /$ PMP22 protein shifted to $18 \mathrm{kD}$ (Fig. 2B).

Furthermore after PNGase F treatment, 18-kD bands were detectable in lanes corresponding to human lung and intestine, as shown in Figure $2 \mathrm{~B}_{\text {; }}$ a faint band was also detected in heart.

No detectable expression of another myelin protein, $\mathrm{PO}$, in the non-neuronal tissues examined was found by Western analysis (data not shown) using monoclonal antibody P07 (Archelos et al. 1993), thus suggesting a lack of contamination from peripheral nerves.

We conclude that Gas3/PMP22 protein is abundantly expressed in the PNS and at reduced levels in non-neu-
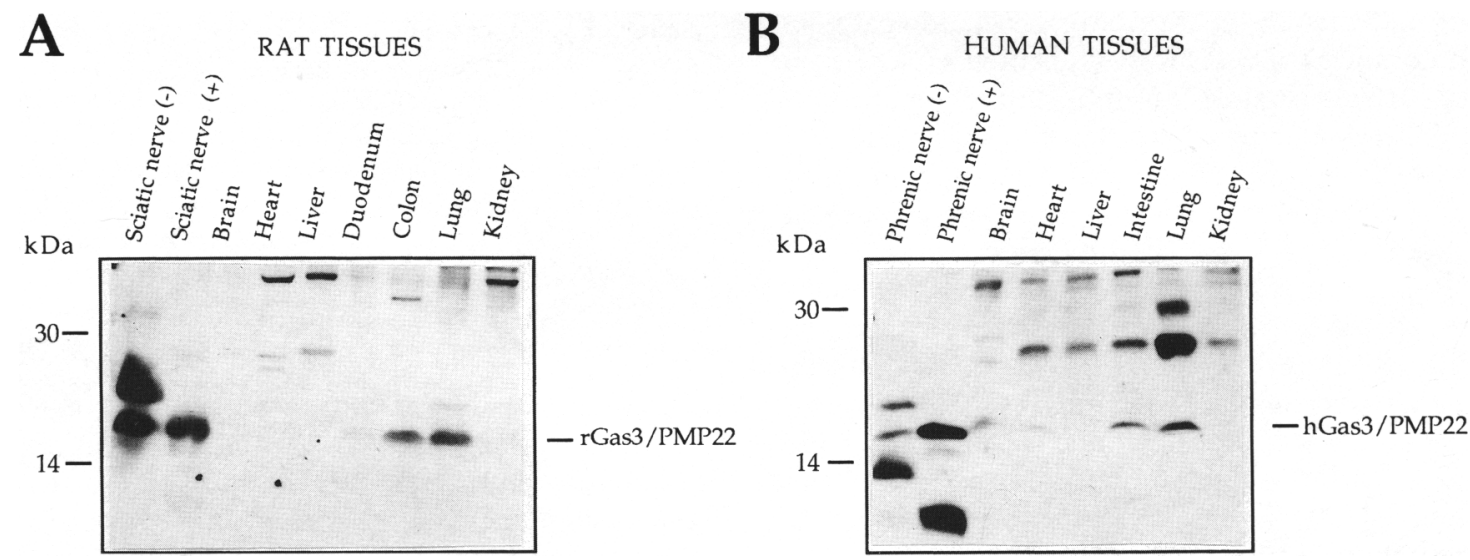

Figure 2. Western blot analysis of Gas3/PMP22 expression in different rat and human tissues. $(A)$ Lysates from different rat tissues were treated with PNGase F before Western analysis. As a positive control rat sciatic nerve extract, untreated $|-|$ or treated $(+\mid$ with PNGase F, was used. Affinity-purified anti-mGas3/PMP22 was used for Western analysis. Rat peripheral nerve lysate was $40 \times 1$ lower than the other lysates. $(B)$ Lysates from different human tissues were treated with PNGase $F$ before Western analysis. As a positive control phrenic nerve extract, untreated $(-)$ or treated $(+\mid$ with PNGase F, was used. Affinity-purified anti-hGas3/PMP22 antibody was used for Western analysis. Human phrenic nerve lysate was $25 \times$ lower than the other tissue lysates. 

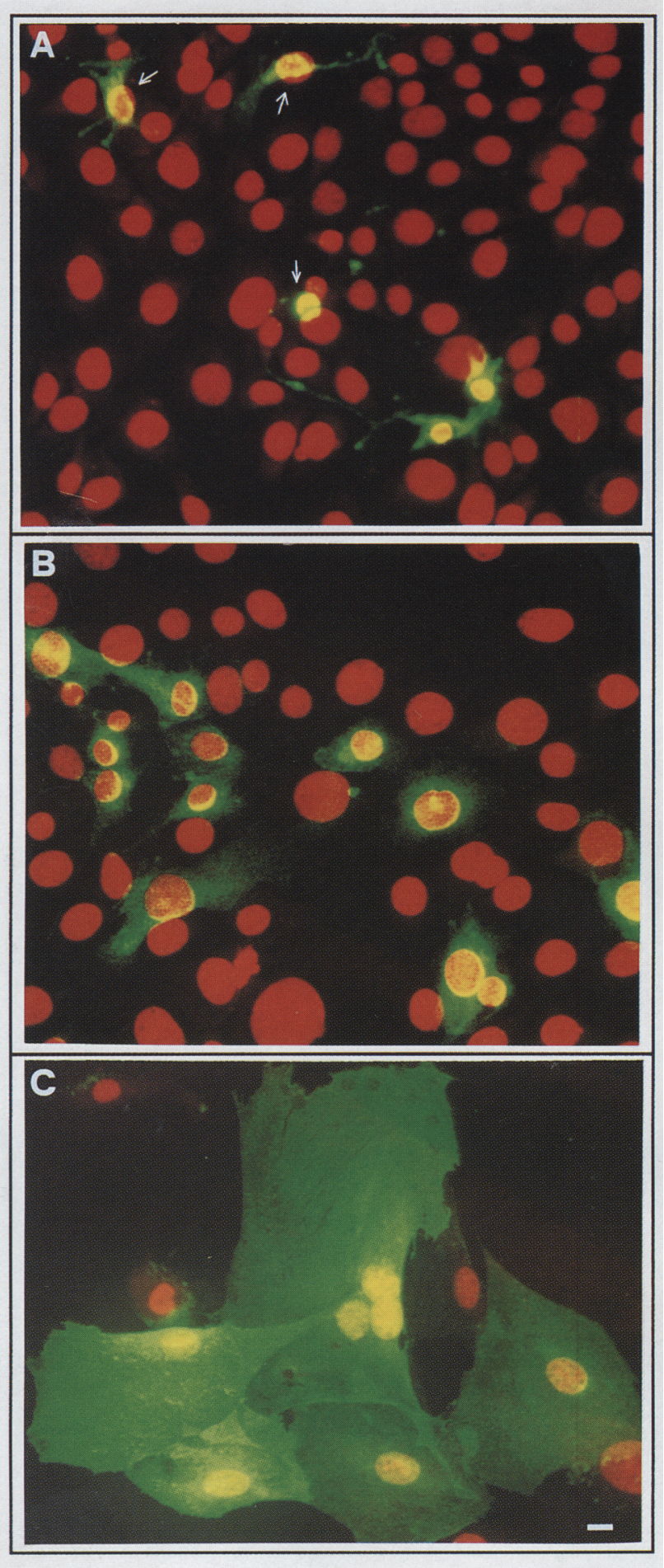

ronal tissues, such as lung and intestine in rat as well as in man.

\section{Overexpression of gas3/PMP22 in cultured cells}

Because both gas3/PMP22 mRNA and protein levels are increased after cell cycle exit, we decided to investigate the effect of ectopic gas3/PMP22 expression on exponen-
Figure 3. Confocal generated overlay showing cellular and nuclear phenotype in gas3/PMP22-microinjected cells. (A) NIH$3 \mathrm{~T} 3$ cells $24 \mathrm{hr}$ after seeding were microinjected with pGDSV7hgas3/PMP22 $(50 \mathrm{ng} / \mu \mathrm{l})$. After $24 \mathrm{hr}$, cells were fixed and processed for immunofluorescence analysis to visualize hGas3/ PMP22 (green) with a specific anti-hGas3/PMP22 antibody and propidium iodide to visualize nuclei (red). Arrows indicate cells detaching from substratum. $(B) \mathrm{NIH}-3 \mathrm{~T} 3$ cells $24 \mathrm{hr}$ after seeding were microinjected with pGDSV7-hgas3/PMP22 (50 ng/ $\mu$ l). Immediately after microinjection $N$-acetyl-L-cysteine was added to the culture medium at a final concentration of $30 \mathrm{~mm}$. After $24 \mathrm{hr}$ cells were fixed and processed for immunofluorescence to visualize hGas3/PMP22 and nuclei. (C) REF-52 cells 24 hr after seeding were microinjected with pGDSV7-hgas3/ PMP22 (50 ng/ $\mu \mathrm{l})$. After $30 \mathrm{hr}$ cells were fixed and processed for immunofluorescence to visualize hGas3/PMP22 and nuclei. Bar, $7.5 \mu \mathrm{m}$.

tially growing NIH-3T3 cells. Human gas3/PMP22 cDNA (Edomi et al. 1993) was cloned in an SV40 expression vector (Del Sal et al. 1994), and nuclear microinjection was used to drive its overexpression.

NIH-3T3 cells growing on a coverslip were microinjected with pGDSV7-hgas3/PMP22 (50 ng/ $\mu$ l), fixed after $24 \mathrm{hr}$, and processed for immunofluorescence analysis to detect hGas3/PMP22 as described in Materials and methods. Because anti-hGas3/PMP22 antibody cross-reacts with mGas3/PMP22 only weakly (data not shown), cells overexpressing hGas3/PMP22 were specifically scored. Figure 3A shows confocal microscopic analysis of a representative field of microinjected NIH-3T3 cells, double stained for Gas3/PMP22 (green) and nuclei (red). NIH-3T3 cells overexpressing Gas3/PMP22 show a dramatic morphological alteration. Cells are loosely attached to the coverslip and are detected on the surface of other cells with a markedly collapsed cellular body and condensed nuclei (Fig. 3A, arrows). Overexpression of various other gas or control genes cloned in the same vector in the same cells under identical experimental conditions never resulted in such effects.

The altered phenotype induced by gas3/PMP22 overexpression was completely abrogated by addition of the reducing agent $N$-acetyl-L-cysteine (NAC) $(30 \mathrm{~mm})$ to the culture medium (Fig. 3B). The same protecting effect could also be obtained with ascorbic acid $(250 \mu \mathrm{M})$ (data not shown), thus giving evidence for a role of reactive oxygen intermediates (ROI) in the generation of gas3/ PMP22-dependent phenotype.

The effect observed in NIH-3T3 fibroblasts after gas3/ PMP22 overexpression is not a universal phenomenon. REF-52 cells that do not express endogenous gas3/ PMP22 (data not shown) appear perfectly normal after ectopic overexpression of gas3/PMP22 under the same experimental conditions used for NIH-3T3 cells (Fig. $3 \mathrm{C})$. To confirm that Gas3/PMP22 protein was produced in REF-52 at a level similar to NIH-3T3 cells, increasing amounts of pGDSV7-hgas3/PMP22 plasmid (50, 100, $150 \mathrm{ng} / \mu \mathrm{l})$ were microinjected in REF-52 and immunofluorescence analysis was performed $30 \mathrm{hr}$ after microinjection. In all cases, no obvious alteration of cell mor- 
phology was ever discerned in REF-52 cells overexpressing gas $3 / P M P 22$. We conclude that the altered phenotype induced by gas $3 / P M P 22$ overexpression is cell type specific and shows some characteristics of apoptosis.

\section{Detailed analysis of gas3/PMP22-induced phenotype in NIH-3T3 fibroblasts}

The term apoptosis was originally proposed to describe a common series of morphological changes that accompany cell death. Plasma membrane blebbing and alteration of the nuclear architecture represent two main features of this process (Kerr et al. 1971; Wyllie et al. 1980). We thus decided to analyze whether these same features could be observed in NIH-3T3 cells overexpressing hgas3/PMP22.

To better define the formation of membrane blebbing we decided to uniformly stain the plasma membrane border. This was achieved by coexpressing gas 3 and gas2, a component of the microfilament system that localizes at the cell border (Brancolini et al. 1992). NIH-3T3 cells were coinjected with pGDSV7-hgas $3 / P M P 22(50 \mathrm{ng} / \mu \mathrm{l})$ and pGDSV7-gas2 $(10 \mathrm{ng} / \mu \mathrm{l})$, and immunofluorescence analysis was performed by double staining for Gas2 and actin. The results of such analyses are shown in Figure 4, $A$ and B, which represents a sequence of horizontal sections from the basal through the apical regions (from left to right) of a coinjected cell stained for Gas2 (Fig. 4A) and actin (Fig. 4B). The features of the plasma membrane of this cell are consistent with structures known as blebs, which are characteristic of the apoptotic phenotype. Membrane blebbing is only noticed in the initial phases of the apoptotic process (Evan et al. 1992) and found in only $2 \%-6 \%$ of the gas $3 / P M P 22$-overexpressing cells. This could represent the rapid kinetics of this process. Parallel analysis of microfilament distribution (Fig. 4B) also shows evident changes in microfilament organization. Confocal analysis showed that increased cell rounding accompanies overexpression of gas $3 /$ PMP22. NIH-3T3 cells overexpressing gas3/PMP22 present a measured cell height of $14.05 \pm 2.05 \mu \mathrm{m}$ when compared with a normal height of $5.73 \mu \mathrm{m} \pm 0.38$, as measured in cell overexpressing gas2 as control gene (data not shown).

We next examined nuclear morphology by confocal microscopy in cells overexpressing Gas3/PMP22 protein by immunofluorecence and propidium iodide staining 24 hr after microinjection. Figure 4, C and D, shows a representative field in which the cells overexpressing gas3/ PMP22 (Fig. 4C) present altered and highly condensed nuclei (Fig. 4D), one of the characteristics of cells undergoing apoptosis.

Another feature of apoptosis, but one that is not universal (Jacobson et al. 1994; Schulze-Osthoff et al. 1994), is DNA fragmentation, which can be detected in situ by the TUNEL technique (Gravieli et al. 1992). Using this method we have not been able to find evidence of DNA fragmentation in cells overexpressing Gas $3 /$ PMP22 protein with respect to a positive control (DNase-induced fragmentation).

To quantitate the apoptotic-like phenomenon induced by gas3/PMP22 overexpression, we correlated the end results of such a process, that is, evident nuclear alteration and decreased cell number. The latter effect should be an expected consequence of the described increased cell rounding preceding complete detachment from adhesion substratum. As a control allowing the quantita-
Figure 4. Detailed analysis of phenotype induced by gas3/PMP22 overexpression in NIH-3T3 fibroblasts. $(A, B)$ Confocal analysis showing membrane blebbing in NIH-3T3 cell overexpressing hyas3/PMP22. NIH-3T3 cells 24 hr after seeding were microinjected with pGDSV7-hgas3/PMP22 $(50 \mathrm{ng} / \mu \mathrm{l})$ and pGDSV7-gas2 $(10 \mathrm{ng} / \mu \mathrm{l})$. After 24 $\mathrm{hr}$ cells were fixed and processed for immunofluorescence analysis to visualize Gas2 $(A)$ and stained with phalloidin-TRITC conjugated to visualize actin filaments $(B)$. Each image represents a section from the basal through the apical regions of the cells. Numbers represent distance from the basal plane. Bar, $7.5 \mu \mathrm{m}$. $(C, D)$ Confocal analysis showing altered cellular and nuclear morphology in NIH-3T3 cells overexpressing hgas3/PMP22. NIH-3T3 cells $24 \mathrm{hr}$ after seeding were microin-

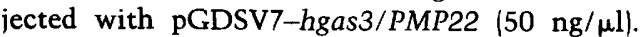
After $24 \mathrm{hr}$ cells were fixed and processed for immunofluorescence analysis to visualize hGas3/ PMP22 $(C)$ and stained with propidium iodide to visualize nuclei $(D)$. The arrow indicates altered nuclei with condensed chromatin. Bar, $7.5 \mu \mathrm{m}$.
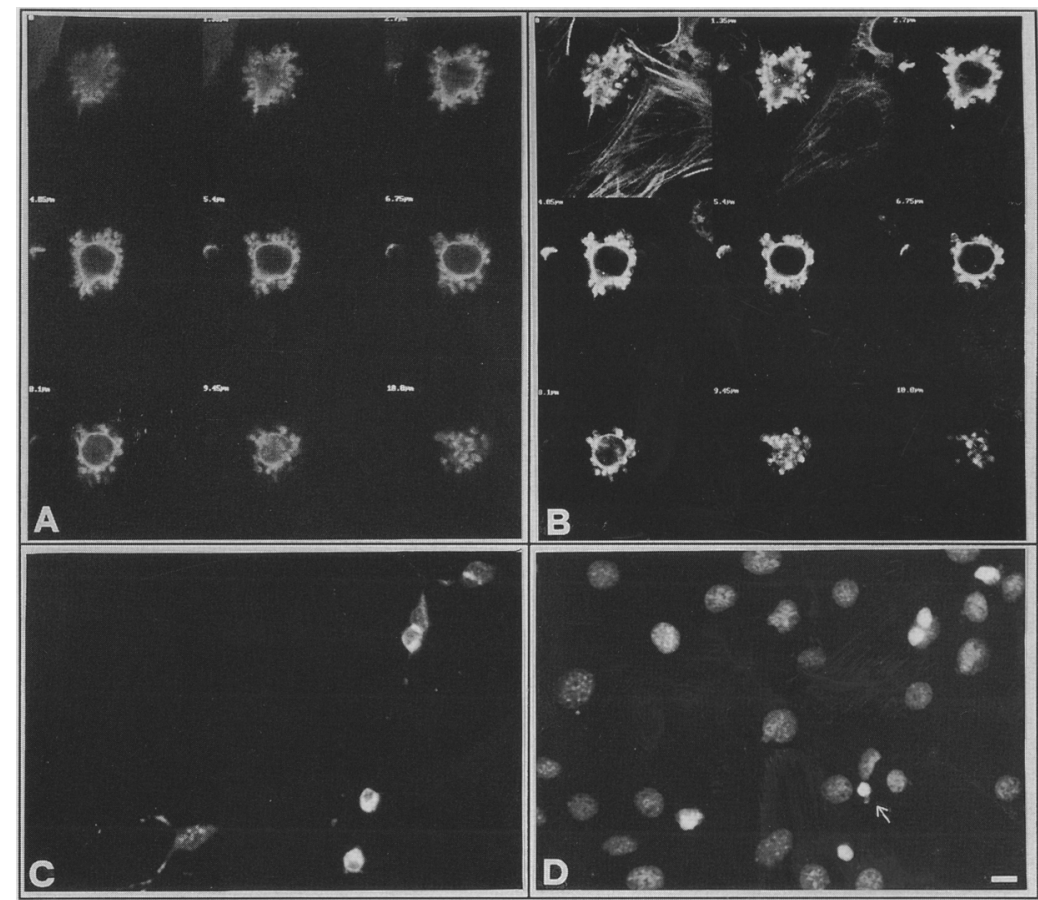
tion of total cells recovered under the same experimental procedure, pGDSV7-gas2 was microinjected in parallel. As reported in Table 1, overexpression of gas3/PMP22 drastically decreases the number of injected cells that are recovered for analysis as compared to the control gas2. A significant fraction of recovered Gas3/PMP22-positive cells presented altered nuclear morphology. Both the described effects and quantitative results are consistent with an apoptotic process induced by gas $3 / P M P 22$. Alteration in nuclear morphology was thus selected as the parameter to quantitate the phenomenon.

\section{Overexpression of gas3/PMP22 CMT1A point mutations shows a significantly reduced apoptotic-like phenotype}

Different point mutations in the human gas3/PMP22 gene have been described in CMT1A patients (Patel and Lupski 1994). The mutations described code for single amino acid substitutions within one of the four putative transmembrane domains of Gas3/PMP22. We evaluated the possibility that such point mutations behave differently from the wild type in their potency to confer the described apoptotic-like phenotype, as quantitated by the degree of nuclear alteration. Mutant human gas3/ PMP22 cDNAs were constructed by introducing point mutations as found in human CMT1A (L16P, S79C, $T 118 M)$ and one mutation carried by mice with the Trembler phenotype (G150D) (Suter et al. 1992a), all cloned in the same expression vector.

We first analyzed the expression of the various mutated products by Western analysis of COS-7 cells transfected with the respective constructs (Fig. 5A). After treatment with PNGase $\mathrm{F}$, a band of $18 \mathrm{kD}$ with the same relative size as found in human phrenic nerve was detected in COS-7 cells transfected with the different gas3/PMP22 constructs but not in mock-transfected

Table 1. Relationship between cell recovery and altered nuclear morphology after gas3/PMP22 overexpression in NIH$3 T 3$ cells

\begin{tabular}{llc}
\hline $\begin{array}{l}\text { Injected } \\
\text { plasmid }\end{array}$ & $\begin{array}{l}\text { Recovered } \\
\text { cells }(\%)\end{array}$ & $\begin{array}{l}\text { Cells showing } \\
\text { altered nuclear } \\
\text { morphology }(\%)\end{array}$ \\
\hline pGDSV7-gas3 & $16.8 \pm 1.0$ & $54.2 \pm 5.4$ \\
pGDSV7-gas2 & $82.0 \pm 4.3$ & 0 \\
\hline
\end{tabular}

Nuclear microinjection of pGDSV7-gas3/PMP22 $(50 \mathrm{ng} / \mu \mathrm{l})$ and pGDSV7-gas2 ( $50 \mathrm{ng} / \mu \mathrm{l}$ ) was performed in NIH-3T3 cells. After $24 \mathrm{hr}$, cells were fixed and analyzed by double immunofluorescence using specific antibodies and FITC-conjugated secondary antibody. The data (mean + S.D.) shown are percentage of FITCpositive cells among the number of injected cells. The altered nuclear morphology as detected by Hoechst 33342 staining is reported as percentage with respect to the recovered cells for both Gas3/PMP22 and Gas-2-positive cells. Cells (250) were injected in each experiment, and data were collected from three independent experiments. cells. The relative expression levels of the different point mutations were comparable with the wild type.

NIH-3T3 cells overexpressing point mutation $L 16 P$, as an example of the different point mutations, show both normal phenotype (Fig. 5B) and normal nuclear morphology (Fig. 5C). In contrast, cells overexpressing wild-type gas3/PMP22, under the same experimental conditions show the previously described altered phenotype (rounded cells) (Fig. 5D), with highly condensed and altered nuclei (Fig. 5E).

We next performed a microinjection analysis using all of the different point mutations. Wild-type or mutant cDNA cloned in the pGDSV7 expression vector was microinjected at a concentration of $50 \mathrm{ng} / \mu \mathrm{l}$ in growing $\mathrm{NIH}-3 \mathrm{~T} 3$ cells. At various times after microinjection, cells were fixed and processed for immunofluorescence to detect Gas3/PMP22. A change in nuclear morphology, as revealed by Hoechst 33342 staining (Fig. 5E), was used to quantitate the apoptotic-like phenotype.

Figure $5 \mathrm{~F}$ shows the relative ability of the mutants to induce the apoptotic-like phenotype in NIH-3T3 cells, as compared to the wild type. All of the point mutations analyzed show significantly decreased ability to induce nuclear condensation with respect to the wild type.

Coexpression of the wild-type and mutants gas3/PMP22 in NIH-3T3 cells correlates with the apoptotic-

like phenotype and Mendelian inheritance

The described point mutations of gas $3 / P M P 22$ fall into two distinct groups according to the mode of inheritance: $L 16 P, S 79 C, G 150 D$ are dominant, whereas $T 118 M$ is the only recessive point mutation described (Roa et al. 1993c). All of the point mutations tested by overexpression have significantly reduced potency in inducing the apoptotic-like phenotype with respect to the wild type. We thus asked whether a correlation could exist between the Mendelian segregation of the mutations and their ability to be dominant or recessive with respect to the apoptotic-like phenotype induced by the wild-type product.

The different mutant plasmids $(25 \mathrm{ng} / \mu \mathrm{l})$ were injected into the nucleus of NIH-3T3 cells together with the same concentration of wild-type plasmid. An immunofluorescence assay was performed $24 \mathrm{hr}$ later, and the results were compared to overexpression of wild-type or the single mutants alone (at a concentration of $50 \mathrm{ng} / \mu \mathrm{l}$ ) performed in parallel. As shown in Figure 6, only coexpression of the recessive $T 118 M$ mutation with a gas $3 /$ PMP22 wild-type construct is as efficient as the wild type alone in inducing the apoptotic-like phenotype. $L 16 P, S 79 C$, and $G 150 D$ mutations, dominant in the CMT1A disease, are also dominant with respect to the ability of the wild type to induce the apoptotic-like phenotype. These mutated products thus behave dominant negatively.

\section{Discussion}

The biological function of Gas3/PMP22 protein is still 
Figure 5. Overexpression of gas $3 / P M P 22$ CMT1A point mutations in NIH- 3T3 cells. $(A)$ Western blot analysis of hgas $3 / P M P 22$ wild-type and different point mutations as expressed by transfected COS-7 cells. $(B, C)$ Immunofluorescence analysis of NIH-3T3 cells overexpressing hgas3/PMP22 point mutations. Exponentially growing NIH-3T3 cells were microinjected with pGDSV7-L16P $(50 \mathrm{ng} / \mu \mathrm{l})$. After $24 \mathrm{hr}$ cells were fixed and processed for immunofluorescence analysis to visualize hgas $3 / P M P 22 / L 16 P$ mutant $(B)$ and stained with Hoechst 33342 to visualize nuclei $(C) .(D, E)$ Exponentially growing NIH-3T3 cells were microinjected with pGDSV7-hgas $3 /$ PMP22 $(50 \mathrm{ng} / \mathrm{ml})$. After $24 \mathrm{hr}$ cells were fixed and processed for immunofluorescence analysis to visualize hGas3/PMP22 $(D)$ and stained with Hoechst 33342 to visualize nuclei $(E) .(F)$ Comparative analysis of the ability to induce an apoptotic-like phenotype in NIH-3T3 cells by the different hgas3/PMP22 point mutations. Exponentially growing $\mathrm{NIH}-3 \mathrm{~T} 3$ cells were microinjected with pGDSV7-hgas3/PMP22 wild type and with different point mutations $(50 \mathrm{ng} / \mu \mathrm{l})$. After various times from microinjection cells were fixed and processed for immunofluorescence analysis to visualize hGas3/PMP22 and stained with Hoechst 33342 to visualize nuclei. Percentages of cells overexpressing hGas3/ PMP22 wild-type or the different point mutations and presenting condensed nuclei lapoptotic-like phenotype/ at different times from microinjection are shown in the histogram analysis. Results represented were obtained from at least three independent experiments and a minimum of 150 cells were scored for each time point. Bar, $7.5 \mu \mathrm{m}$.
A


unknown. Its high expression level in myelin-forming Schwann cells has suggested a major structural role as a myelin protein involved in membrane compaction. However, its expression has been originally linked with growth arrest in NIH-3T3 cells (Manfioletti et al. 1990), thus suggesting a more general regulatory role.

Here we report that ectopic expression of gas $3 / P M P 22$ cDNA in NIH-3T3 fibroblasts is associated with a general alteration in cellular shape involving membrane blebbing, nuclear condensation, and cellular rounding, which are all features accompanying the apoptotic process (Kerr et al. 1971; Wyllie et al. 1980). This apoptoticlike phenotype is efficiently inhibited by addition of reducing agents in the medium, thus, indicating that the process depends on the presence of reactive oxygen intermediates, which are well known inducers of apoptosis (Hockenbery et al. 1993). Moreover, the lack of the apoptotic-like phenotype by gas $3 / P M P 22$ overexpression in
REF- 52 cells strongly suggests a cell type-specific responsiveness. This evidence could suggest that Gas3/PMP22 does not induce apoptosis directly, but permits cellular entry to a state in which apoptosis becomes more readily accessible.

When the gas3/PMP22 point mutations associated with CMT1A and Trembler were similarly analyzed by overexpression in NIH-3T3 cells, all of the mutants showed a significantly reduced ability to trigger the apoptotic-like phenotype as compared to the wild type.

Mutations L16P, S79C (human), and G150D (murine), display a pathological phenotype evident in heterogozygotes (dominant phenotype) (for review, see Patel and Lupski 1994). The T118M substitution in human Gas3/ PMP22 protein is the only identified mutant allele that segregates as a recessive trait (Roa et al. 1993c). CMT1A symptoms in patients with the $T 118 \mathrm{M}$ substitution become evident only in the pseudodominant condition as- 


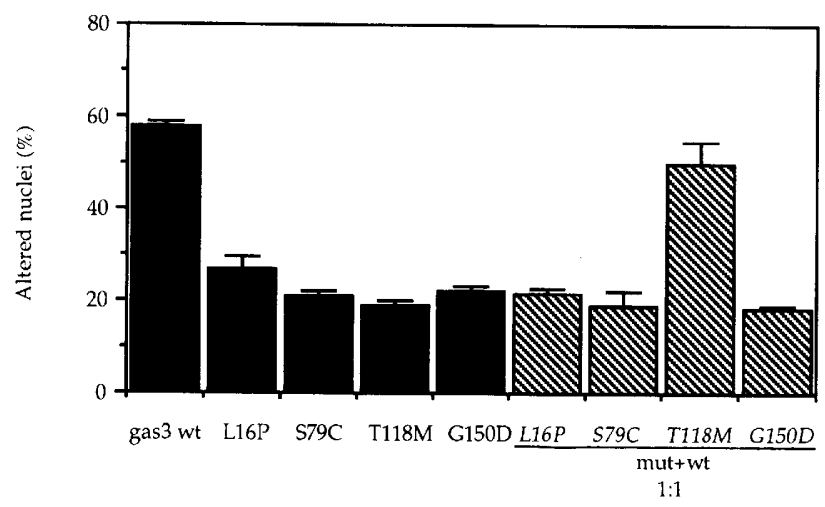

Figure 6. Coexpression of wild-type and mutant hgas3/PMP22 in NIH-3T3 cells. NIH-3T3 cells $24 \mathrm{hr}$ after seeding were microinjected with pGDSV7-hgas3/PMP22 wild-type, pGDSV7L16P, pGDSV7-S79C, pGDSV7-T118M, and pGDSV7-G150D $(50 \mathrm{ng} / \mu \mathrm{l})$. For coexpression experiments wild-type and mutant constructs were coinjected at a concentration of $25 \mathrm{ng} / \mu \mathrm{l}$ each. Cells were fixed $24 \mathrm{hr}$ after microinjection and processed for immunofluorescence analysis to visualize hGas3/PMP22 and stained with Hoechst 33342 to visualize nuclei. Percentages of cells overexpressing hGas3/PMP22 wild type together with the different point mutations and presenting condensed nuclei (apoptotic-like phenotype) are shown in the diagram analysis. Results were obtained from at least three independent experiments with a minimum of 150 cells scored for each experiment.

sociated with HNPP disease, where one copy of the gas3/ PMP22 locus on a homologous chromosome 17 is deleted (Nicholson et al. 1994). On the contrary, in the heterozygous condition $T 118 \mathrm{M}$-carrying individuals are asymptomatic (Roa et al. 1993b). Given this genetic basis we have coexpressed the different mutants with the wild-type gas3/PMP22 cDNA, thus reproducing a heterozygous condition. All dominant mutations (L16P, $S 79 C$, and $G 150 D$ ) when coexpressed with the wild type significantly suppress the typical wild-type apoptoticlike phenotype. On the contrary, coexpression of $T 118 M$ with wild type is unable to suppress the effect of wild type, thus confirming the recessive nature of the $T 118 M$ gas3/PMP22 mutation. Therefore the apoptotic-like phenotype associated with wild-type gas $3 / P M P 22$ gene product overexpression is strictly linked with the genetics of the disease suggesting that mutations $L 16 P, S 79 C$, and $G 150 D$ act in a dominant negative fashion.

We can thus provocatively speculate that regulation of susceptibility to apoptosis by Gas3/PMP22 could play a relevant role in the control of Schwann cell-differentiation. Control of Schwann cell renewal in vivo should reflect the balance of the various alternative fates, namely continued cellular division, growth arrest, differentiation into myelin-forming Schwann cells, or lastly apoptosis. Defects in modulating cellular responsiveness to apoptosis, evidenced in the Gas3/PMP22 mutants, could thus explain continued proliferation and a consequent lack of correct differentiation as found in CMT1A. However, this function of Gas3/PMP22 does not exclude a second structural role that it may play during myelin formation or maintenance given the extremely high level of expression of this product. This second function should only be compatible with suppression of its apoptotic modulatory function, which in turn depends on the cellular responsiveness. It is common knowledge that the capacity of an individual cell to execute a suicidal response following a death stimulus can vary markedly within a given differentiation pathway.

Possessing a dual function, both as a regulator of apoptosis and as a structural component in a given differentiation pathway, could be evolutionarily economical and logical. It is intriguing that a similar dual function in controlling apoptosis and myelin formation has been invoked for myelin proteolipid protein (PLP), which is structurally related to Gas3/PMP22 and a major component of the myelin in the central nervous system (CNS). In this case, a particular point mutation (rumpshaker) has allowed the dissection of these two functions of PLP (Schneider et al. 1992; Pham-Dinh et al. 1993; Kagawa et al. 1994).

As shown previously, Gas3/PMP22 protein is expressed at much lower levels in nonmyelin-forming cells or tissues. We should thus exclude here that Gas3/ PMP22 exerts a myelin-specific structural role, leaving the apoptotic regulatory function as the most conceivable one.

Apoptosis should be considered as part of the homeostatic balance that regulates $\mathrm{G}_{0}$ where Gas3/PMP22 expression is increased. It has been established that withdrawal from the cell cycle after growth factor deprivation increases cellular sensitivity toward apoptosis (Raff 1992; Hoffman and Liebermann 1994). Increased expression of Gas3/PMP22 should thus represent an obvious consequence.

\section{Materials and methods \\ Gas3 expression in Escherichia coli}

The glutathione $S$-transferase (GST)-mGas3 and GST-hGas3 fusion proteins, both comprising the region from amino acids 16 to 63 of mouse and human Gas3, were constructed by PCR using pBluescript-mgas3 (Manfioletti et al. 1990) or pBluescript-hgas3 (Edomi et al. 1993) as template. The sense primers oligonucleotide 16 (5' -ACTAGGATCCTGGTGCTGCTGTTCGTCTCC-3'), containing a BamHI cloning site, and the reverse primer oligonucleotide 63 (5'-GCAAGAATTCTGCAGCCATTCGTTTGGTGAT-3'), containing an EcoRI cloning site, were used. Amplified fragments were gel purified, digested with $B a m H I$ and EcoRI, and then subcloned in the pGEX-3X vector (Pharmacia Biotech). Fusion proteins were expressed in E. coli after induction with $1 \mathrm{mM}$ IPTG for $3 \mathrm{hr}$, after which bacteria were pelleted and lysed. The resulting inclusion bodies were solubilized in SDS-sample buffer $2 \%$ SDS, $60 \mathrm{~mm}$ Tris at $\mathrm{pH}$ $6.8,10 \%$ glycerol, $2 \% \beta M E$ ) by boiling for $10 \mathrm{~min}$. Proteins were separated on a preparative SDS-polyacrylamide gel, and the band corresponding to the fusion protein was electroeluted as described previously (Brancolini et al. 1992).

To obtain the maltose-binding protein (MBP)-Gas3 fusion proteins MBP-mGas3 and MBP-hGas3, the amplified fragments described above were filled in with Klenow and blunt ligated into pMALc2 vector after digestion with BamHI and EcoRI (New England Biolabs). Expression of the fusion proteins in E. coli was achieved by induction with $1 \mathrm{~mm}$ IPTG for $1 \mathrm{hr}$. 
MBP-Gas3 fusion proteins were purified from bacteria as recommended by the vendor (New England Biolabs).

\section{Preparation of the antisera and affinity purification of antibodies}

Rabbits were injected with $300 \mu \mathrm{g}$ of purified bacterial GSTmGas 3 or GST-hGas3 fusion proteins mixed 1:1 with complete Freund's adjuvant. Subsequently they were injected with the same amount of protein in incomplete Freund's adjiuvant every 3 weeks. Anti-hGas 3 and anti-mGas 3 antibodies were affinity purified, by means of Affi-Prep 10 support (Bio-Rad Laboratories) coupled to fusion proteins MBP-hGas3 and MBP-mGas3. The respective fusion protein $(1 \mathrm{mg}$ ) was coupled to Affi-Prep 10 support, and the affinity matrix was used to obtain anti-hGas3 and anti-mGas 3 antibodies. Immune serum $(2 \mathrm{ml})$ was incubated batchwise with the matrix, and after extensive PBS washing in the column, the antibodies were eluted with $0.25 \mathrm{M}$ glycine at $\mathrm{pH} 2.8$. Fractions of $400 \mu \mathrm{l}$ were collected and neutralized with $100 \mu \mathrm{l}$ of $2 \mathrm{M}$ Tris at $\mathrm{pH} 8$.

\section{Construction of gas3/PMP22 wild type and mutants for expression}

For expression in eukaryotic cells the hgas 3 open reading frame (ORF) was subcloned in the pGDSV7 vector (Del Sal et al. 1994). ORF hgas3 was constructed by PCR using pBluescript-hgas3 (Edomi et al. 1993) as template. The sense primer oligonucleotides 5' (5'-GAGTGAATTCAACTCCGCTGAGCAGAACTT $-3^{\prime} \mid$, containing an EcoRI cloning site, and the reverse primer oligonucleotide $3^{\prime}$ (5'-GAGTAAGCTTTCATCGCGT TTCCGCAAGA-3'), containing a HindIII cloning site were used. The amplified fragment was gel purified, digested with EcoRI and HindIII, and subcloned in the pGDSV7 vector (Del Sal et al. 1994).

A site-directed mutagenesis method by overlap extension through PCR (Ho et al. 1989) was used to produce the point mutation forms of ORF hgas3. As external primers the oligonucleotide $5^{\prime}$ and $3^{\prime}$ were used. The pair of complementary inverse oligonucleotides containing the mutated nucleotide were the following:

for the mutant $\mathrm{L} \rightarrow \mathrm{P}$ at position 16 ,

ol 1 (5'-TCGCGGTGCCGGTGCTGCT-3') ol 1' (5'-AGCAGCACCGGCACCGCGA-3')

for the mutant $\mathrm{S} \rightarrow \mathrm{C}$ at position 79 ,

ol 2 (5'-GCATTCTGTGTCTGTTCCT-3') ol 2' (5'-AGGAACAGACACAGAATGC-3')

for the mutant $\mathrm{T} \rightarrow \mathrm{M}$ at position 118 ,

ol 3 (5'-CCATCTACATGGTGAGGCA-3') ol 3' (5'-TGCCTCACCATGTAGA TGG-3')

for the mutant $G \rightarrow D$ at position 150 ,

ol 4 (5'-TTCTCAGCGATGTCATCTA-3') ol 4' (5'-TAGATGACATCGCTGAGAA-3')

All constructs generated were sequenced using an automated (ALF) system to check for the respective mutations introduced and the translating fidelity of the inserted PCR fragments.

\section{Cell lines and culture conditions}

NIH-3T3, REF-52, and COS-7 cells were grown in Dulbecco's modified Eagle medium (DMEM) supplemented with $10 \%$ fetal calf serum (FCS), penicillin (100 U/ml), and streptomycin (100 $\mu \mathrm{g} / \mathrm{ml})$. In each experiment $4 \times 10^{4}$ cells $/ \mathrm{ml}$ were seeded in 35 mm petri dishes.

For serum starvation, medium was changed to $0.5 \%$ FCS when NIH-3T3 cells were subconfluent; cells were then left in this medium for $48 \mathrm{hr}$. After incubation with $50 \mu \mathrm{M}$ bromodeoxyuridine (BrdU) for an additional $\mathrm{l} \mathrm{hr},<3 \%$ of the nuclei was labeled.

For density-dependent inhibition $24 \mathrm{hr}$ after plating (considered as the starting point for growing cells) the medium was changed every 2 days. After 4 days in culture, incubation with BrdU for $2 \mathrm{hr}$ resulted in $5 \%$ incorporation in the nuclei.

Transfection experiments in COS-7 cells were performed using the DEAE-dextran method. Cells were grown in $35-\mathrm{mm}$ petri dishes, washed twice with DMEM, and added with $400 \mu \mathrm{l}$ of DMEM containing $0.5 \mathrm{mg} / \mathrm{ml}$ of DEAE-dextran and $1.2 \mu \mathrm{g}$ of DNA. After incubation at $37^{\circ} \mathrm{C}$ for $30 \mathrm{~min}$, DMEM containing $10 \%$ FCS and chloroquine $(100 \mu \mathrm{M})$ was added and incubation was prolonged for $4 \mathrm{hr}$. Cells were then washed twice with DMEM and cultured for 2 days in DMEM containing $10 \%$ FCS.

\section{Immunoblotting}

Preparation of cellular or organ extracts was performed as described previously (Brancolini et al. 1992). PNGase F treatment lysates were prepared in $0.5 \%$ SDS, $1 \% \beta M E$, and boiled for 10 min. Samples were then made $50 \mathrm{~mm}$ sodium phosphate at $\mathrm{pH}$ $7.5,1 \%$ NP-40, and 500 NEB (New England Biolabs) units of $N$-glycosidase F (PNGase F) (New England Biolabs) was added. Incubation was performed for $2 \mathrm{hr}$ at $37^{\circ} \mathrm{C}$. After adding SDSsample buffer, protein samples were separated by SDS-PAGE using $10 \%$ polyacrylamide gels and Tris/tricine buffer as described (Schagger and von Jagow 1987).

For Western blotting proteins were transferred to $0.2-\mu \mathrm{m}$ pore-sized nitrocellulose (S\&S) using a semidry blotting apparatus (Bio-Rad) (transfer buffer, 20\% methanol, $48 \mathrm{~mm}$ Tris, $39 \mathrm{~mm}$ glycine, $0.0375 \%$ SDS). After staining with Ponceau S, the nitrocellulose sheets were saturated for $2 \mathrm{hr}$ in PBS, $0.5 \%$ casein, and $0.3 \%$ Tween 20 and incubated overnight at room temperature in the same buffer with the anti-Gas3 antibody. Blots were then rinsed three times with PBS, $0.3 \%$ Tween 20 , reacted with alkaline phosphatase-conjugated goat anti-rabbit antibody for 2 $\mathrm{hr}$ at room temperature, and treated for chemiluminescent detection as recommended by the vendor (Tropix, Bedford, MA). Mouse mAb P07 (Archelos et al. 1993) against PNS myelin protein P0 was kindly provided from L. Wrabetz (Istituto Scientifico S. Raffaele, Milan, Italy).

\section{Immunofluorescence microscopy}

For indirect immunofluorescence microscopy, NIH-3T3 or REF52 cells were grown under the described conditions and then fixed with $3 \%$ paraformaldehyde in PBS for $20 \mathrm{~min}$ at room temperature. Fixed cells were washed with PBS $/ 0.1 \mathrm{M}$ glycine at $\mathrm{pH} 7.5$ and then permeabilized with cold acetone for $1 \mathrm{~min}$ at $-20^{\circ} \mathrm{C}$. The coverslips were treated with the first antibody (anti-hGas3/PMP22 diluted in PBS 3\% BSA) for $1 \mathrm{hr}$ in a moist chamber at $37^{\circ} \mathrm{C}$. To detect Gas2 protein, NIH-3T3 cells were incubated with a rabbit anti-Gas2 antibody (Brancolini et al. 1992). They were then washed with PBS three times, followed by incubation with FITC-conjugated anti-rabbit second antibody (Dako) for $1 \mathrm{hr}$ at $37^{\circ} \mathrm{C}$. For detection of actin filaments, TRITC-phalloidin (Sigma) was used. Nuclei were labeled with Hoechst 33342 dye or propidium iodide $(5 \mu \mathrm{M})$ (Sigma). Finally, cells were examined by epifluorescence with a Zeiss Axiovert 35 microscope or a Zeiss laser scan microscope (LSM 410) 
equipped with a $488 \lambda$ argon laser and a $543 \lambda$ helium neon laser. The following set of filters were used: rhodamine (BP546, FT580, LP 590), fluorescein (450-490, FT 510, LP520), and Hoechst 33342 (BP 365, FT 395, LP 397).

\section{Microinjection}

Microinjection was performed using the Automated Injection System (Zeiss Oberkochen, Germany) as described previously (Del Sal et al. 1992). Cells were injected with $50 \mathrm{ng} / \mu \mathrm{l}$ of expression vector (Del Sal et al. 1994). Each cell was injected for $0.3 \mathrm{sec}$ at a constant pressure of 150 hecto-Pascal. When used, $\mathrm{N}$-acetyl-cysteine $30 \mathrm{mM}$ (Sigma) or ascorbic acid $250 \mu \mathrm{M}$ (Sigma) was added to the culture medium immediately after microinjection.

\section{Acknowledgments}

We are indebted to Dr. Maria Elisabetta Ruaro for her invaluable and expert help in microinjection and immunofluorescence experiments. We are grateful to our many colleagues for their advice and help, in particular to Drs. Giannino Del Sal and Stefano Gustincich. We also thank Ms. Stefania Marzinotto for providing the cells used in the experiments and Dr. Federico Volpatti for providing the oligonucleotides. We are indebted to Dr. Lawrence Wrabetz for his very useful comments and suggestions on this manuscript and for providing mAb P07. This work was supported by funding of Telethon-Progetto no. 424 and Associazione Italiana per la Ricerca sul Cancro, Progetto speciale oncosoppressori to Claudio Schneider.

The publication costs of this article were defrayed in part by payment of page charges. This article must therefore be hereby marked "advertisement" in accordance with 18 USC section 1734 solely to indicate this fact.

\section{References}

Archelos, J.J., K. Roggenbuck, J. Schneider-Schaulies, C. Linington, K.V. Toyka, and H.P. Hartung. 1993. Production and characterization of monoclonal antibodies to the extracellular domain of P0. J. Neurosci. Res. 35: 46-53.

Brancolini, C., S. Bottega, and C. Schneider. 1992. Gas2, a growth arrest-specific protein, is a component of the microfilament network system. J. Cell Biol. 117: 1251-1261.

Chance, P.F., M.K. Alderson, K.A. Leppig, M.W. Lensch, N. Matsunami, B. Smith, P.D. Swanson, S.J. Odelberg, C.M. Disteche, and T.D. Bird. 1993. DNA deletion associated with hereditary neuropathy with liability to pressure palsies. Cell 72: 143-151.

Del Sal, G., E. Ruaro, L. Philipson, and C. Schneider. 1992. The growth arrest specific gene, gas 1 , is involved in growth suppression. Cell 70: 595-607.

Del Sal, G., G. Manfioletti, S. Gustincich, E. Ruaro, and C. Schneider. 1994. New lambda plasmid vectors for expression cloning in mammalian cells. BioTechnology 16: 134-138.

Edomi, P., A. Martinotti, M.P. Colombo, and C. Schneider. 1993. Sequence of human GAS3/PMP22 full-length cDNA. Gene 126: 289-290.

Evan, G.I., A.H. Wyllie, C.S. Gilbert, T.D. Littlewood, H. Land, M. Brooks, C.M. Waters, L.Z. Penn, and D.C. Hancock. 1992. Induction of apoptosis in fibroblasts by c-myc protein. Cell 69: 119-128.

Gravieli, Y., Y. Sherman, and A. Ben-Sasson. 1992. Identification of programmed cell death in situ via specific labeling of nuclear DNA fragmentation. J. Cell Biol. 119: 493-501.

Ho, S.N., H.D. Hunt, R.M. Horton, J.K. Pullen, and L.R. Pease.
1989. Site-directed mutagenesis by overlap extension using the polimerase chain reaction. Gene 77: 51-59.

Hockenbery, D.M., Z.N. Oltvai, X.M. Yin, C.L. Milliman, and S.J. Korsmeyer. 1993. Bcl-2 functions in an antioxidant pathway to prevent apoptosis. Cell 75: 241-251.

Hoffman, B. and D.A. Liebermann. 1994. Molecular controls of apoptosis: differentiation/growth arrest primary response genes, proto-oncogenes and tumor suppressor genes as positive \& negative modulators. Oncogene 9: 1807-1812.

Ionasescu, V., R. Ionasescu, C. Searby, and D.F. Barker. 1993. Charcot-Marie-Tooth neuropathy type $1 \mathrm{~A}$ with both duplication and non-duplication. Hum. Mol. Genet. 2: 405-410.

Jacobson, M.D., J.F. Burne, and M.C. Raff. 1994. Programmed cell death and Bcl-2 protection in the absence of nucleus. EMBO I. 13: 1899-1910.

Kagawa, T., K. Ikenaka, Y. Inoue, S. Kuriyama, T. Tsujii, J. Nakao, K. Nakajima, J. Argua, H. Okano, and K. Mikoshiba. 1994. Glial cell degeneration and hypomyelination caused by overexpression of myelin proteolipid protein gene. Neuron 13: $427-442$.

Kerr, J.F.R. 1971. Shrinkage necrosis: a distinct mode of cellular death. J. Pathol. 105: 13-20.

Lupski, J.R., R. Montes de Oca Luna, S. Slaugenhaupt, L. Pentao, V. Guzzetta, B.J. Trask, O. Saucedo-Cordenas, D.F. Barker, J.M. Killian, C.A. Garcia, A. Chakravarti, and I.P. Patel. 1991. DNA duplication associated with Charcot-MarieTooth disease type 1A. Cell 66: 219-232.

Manfioletti, G., M.E. Ruaro, G. Del Sal, L. Philipson, and C. Schneider. 1990. A growth arrest-specific (gas) gene codes for a membrane protein. Mol. Cell. Biol. 10: 2924-2930.

Matsunami, N., B. Smith, L. Ballard, M.W. Lensch, M. Robertson, H. Albertsen, C.O. Hanemann, H.W. Müller, T.D. Bird, R. White, and P.F. Chance. 1992. Peripheral myelin protein22 gene maps in the duplication in chromosome $17 \mathrm{p} 11.2$ associated with Charcot-Marie-Tooth type 1A. Nature Genet. 1: 176-179.

Nicholson, G.A., L.J. Valentijn, A.K. Cherryson, M.L. Kennerson, T.L. Bragg, R. Dekroon, D.A. Ross, J.D. Pollard, J.G. Mcleod, P.A. Bolhuis, and F. Baas. 1994. A frame shift mutation in the PMP22 gene in hereditary neuropathy with liability to pressure palsies. Nature Genet. 6: 263-266.

Pareek, S., U. Suter, G.J. Snipes, A.A. Welcher, E.M. Shooter, and R.A. Murphy. 1993. Detection and processing of peripheral myelin protein PMP22 in cultured Schwann cells. I. Biol. Chem. 268: 10372-10379.

Patel, I.P. and J.R. Lupski. 1994. Charcot-Marie-Tooth disease: a new paradigm for the mechanism of inherited disease. Trends Genet. 10: 128-133.

Pham-Dinh, D., O. Boespflug-Tanguy, C. Mimault, A. Cavagna, G. Giraud, G. Leberre, B. Lemarec, and A. Dautigny. 1993. Pelizaeus-Merzbacher disease: A frameshift deletion/insertion event in the myelin proteolipid gene. Hum. Mol. Genet. 2: 465-467.

Raff, M.C. 1992. Social controls on cell survival and cell death. Nature 356: 397-400.

Re, F., G. Manenti, M.G. Borrello, M.P. Colombo, J.H. Fisher, M.A. Pierotti, G. Della Porta, and T.A. Dragani. 1992. Multiple molecular alteration in mouse lung tumors. Mol. Carcinog. 5: 155-160.

Roa, B.B., C.A. Garcia, U. Suter, D.A. Kulpa, C.A. Wise, J. Müller, A.A. Welcher, G.J. Snipes, E.M. Shooter, and P. Patel. 1993a. Charcot-Marie-Tooth disease type 1A. Association with a spontaneous point mutation in the PMP22 gene. N. Engl. J. Med. 329: 96-101.

Roa, B.B., C.A. Garcia, L. Pentao, J.M. Killian, B.J. Trask, U. Suter, G.J. Snipes, R. Ortiz-Lopez, E.M. Shooter, I.P. Patel, 
Fabbretti et al.

and J.R. Lupski. 1993b. Evidence for a recessive PMP22 point mutation in Charcot-Marie-Tooth disease type 1A. Nature Genet. 5: 189-194.

Roa, B.B., P.J. Dyck, H.G. Marks, P.F. Chance, and J.R. Lupski. 1993c. Dejerine-Sottas syndrome associated with point mutation in the peripheral myelin protein 22 (PMP22) gene. Nature Genet. 5: 269-273.

Schagger, H. and G. von Jagow. 1987. Tricine-sodium dodecyl sulfate-polyacrylamide gel electrophoresis for the separation of proteins in the range from 1 to $100 \mathrm{kDa}$. Anal. Biochem. 166: $368-379$.

Schneider, A., P. Montague, I. Griffiths, M. Fanarraga, P. Kennedy, P. Brophy, and K.A. Nave. 1992. Uncoupling of hypomyelination and glial cell death by a mutation in the proteolipid protein gene. Nature 358: 758-761.

Schneider, C., R.M. King, and L. Philipson. 1988. Genes specifically expressed at growth arrest of mammalian cells. Cell 54: 787-793.

Schulze-Osthoff, K., H. Walczak, W. Droge, and P.H. Krammer. 1994. Cell nucleus and DNA fragmentation are not required for apoptosis. I. Cell. Biol. 127: 15-20.

Snipes, G.J., U. Suter, A.A. Welcher, and E.M. Shooter. 1992. Characterization of a novel peripheral nervous system myelin protein (PMP22/SR13). I. Cell. Biol. 117: 225-238.

Spreyer, P., G. Kuhn, C.O. Hanemann, C. Gillen, H. Schaal, R. Kuhn, G. Lemke, and H.W. Müller. 1991. Axon-regulated expression of a Schwann cell transcript that is homologous to a "growth arrest-specific" gene. EMBO J. 10: 3661-3668.

Suter, U., A.A. Welcher, T. Ozcelik, G.J. Snipes, B. Kosaras, U. Francke, S. Billings-Gagliardi, R.L. Sidman, and E.M. Shooter. 1992a. Trembler mouse carries a point mutation in a myelin gene. Nature 356: 241-244.

Suter, U., J.J. Moskow, A.A. Welcher, G.J. Snipes, B. Kosaras, R.L. Sidman, A.M. Buchberg, and E.M. Shooter. 1992b. A leucine-to-proline mutation in the first transmembrane domain of the $22-\mathrm{kDa}$ peripheral myelin protein in the trem. bler-J mouse. Proc. NatI. Acad. Sci. 89: 4382-4386.

Suter, U., A.A. Welcher, and G.J. Snipes. 1993. Progress in the molecular understanding of hereditary peripheral neuropathies reveals new insights into the biology of the peripheral nervous system. Trends Neurosci. 16: $50-56$.

Timmermann, V., E. Nelis, W. Van Hul, B.W. Nieuwenhuijsen, K.L. Chen, S. Wang, B.K. Othman, B. Cullen, R.J. Leach, C.O Hanemann, P. De Jonghe, P. Raeymaekers, G.-J.B. van Ommen, J.J. Martin, H.W. Müller, J.M. Vance, K.H. Fischbeck, and C. Van Broeckhoven. 1992. The peripheral myelin protein gene PMP22 is contained within the Charcot-MarieTooth disease type 1A duplication. Nature Genet. 1: 171175

Valentijn, L.J., F. Baas, R.A. Wolterman, J.E. Hoogendijk, N.H.A. van den Bosh, I. Zorn, A.A.W.M. Gabreels-Festen, M. de Visser, and P.A. Bolhuis. 1992a. Identical point mutations of PMP-22 in Trembler-J mouse and Charcot-Marie-Tooth disease type 1A. Nature Genet. 2: 288-291.

Valentijn, L.J., P.A. Bolhuis, I. Zorn, J.E. Hoogendijk, N. van den Bosch, G.W. Hensels, V.P. Stanton Jr, D.E. Housman, K.H. Fishbeck, D.A. Ross, G.A. Nicholson, E.J. Meershoek, H.G. Dauwerse, G.-J.B. van Ommen, and F. Baas. 1992b. The peripheral myelin gene PMP-22/GAS-3 is duplicated in Charcot-Marie-Tooth disease type 1A. Nature Genet. 1: 166-170.

Welcher, A.A., U. Suter, M. De Leon, G.J. Snipes, and E.M. Shooter. 1991. A myelin protein is encoded by the homologue of a growth arrest-specific gene. Proc. Natl. Acad. Sci. 88: 7195-7199.

Wyllie, A.H., J.F.R. Kerr, and A.R. Currie. 1980. Cell death: The significance of apoptosis. Int. Rev. Cytol. 68: 251-307. 


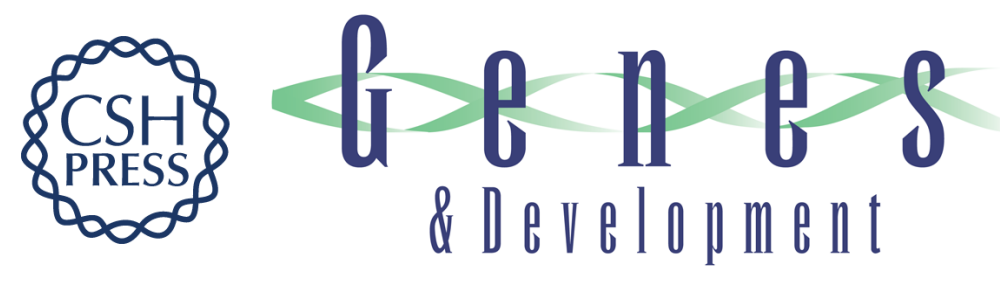

\section{Apoptotic phenotype induced by overexpression of wild-type gas3/PMP22: its relation to the demyelinating peripheral neuropathy CMT1A.}

E Fabbretti, P Edomi, C Brancolini, et al.

Genes Dev. 1995, 9:

Access the most recent version at doi:10.1101/gad.9.15.1846

References This article cites 41 articles, 8 of which can be accessed free at:

http://genesdev.cshlp.org/content/9/15/1846.full.html\#ref-list-1

License

Email Alerting Service

Receive free email alerts when new articles cite this article - sign up in the box at the top right corner of the article or click here.

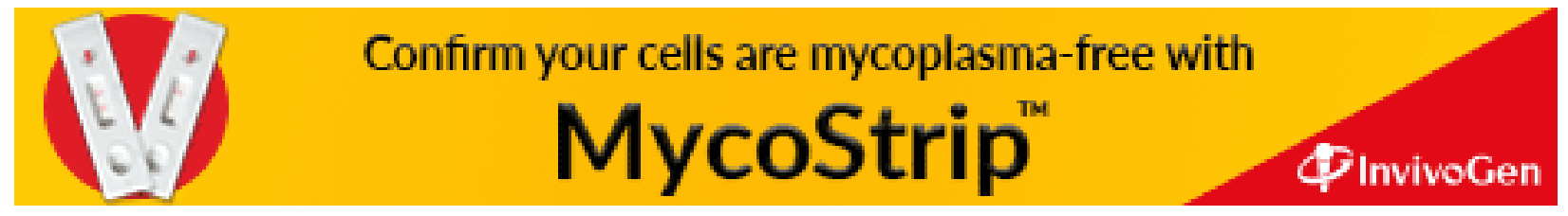

